OPEN ACCESS

Edited by:

Mihajlo (Michael) Jakovljevic Department of Health Economics,

Lund University, Sweden

Reviewed by: Zafer Çaliskan,

Hacettepe University, Turkey Mohsen Shams,

Yasuj University of Medical

Sciences, Iran

*Correspondence:

Ronny Westerman

ronny.westerman@bib.bund.de

Specialty section: This article was submitted to

Health Economics,

a section of the journal Frontiers in Public Health

Received: 03 May 2019 Accepted: 21 June 2019 Published: 10 July 2019

Citation:

Westerman R and Mühlichen M (2019) Avoidable Cancer Mortality in Germany Since Reunification:

Regional Variation and Sex Differences.

Front. Public Health 7:187.

doi: 10.3389/fpubh.2019.00187

\section{Avoidable Cancer Mortality in Germany Since Reunification: Regional Variation and Sex Differences}

\author{
Ronny Westerman ${ }^{1 *}$ and Michael Mühlichen ${ }^{2}$ \\ ${ }^{1}$ Competence Center Mortality-Follow-Up, German National Cohort (GNC), Federal Institute for Population Research, \\ Wiesbaden, Germany, ${ }^{2}$ Federal Institute for Population Research, Wiesbaden, Germany
}

Background: Regional comparisons of cancer-related mortality in Germany are traditionally focused on disparities between East and West Germany. Recent improvements in all-cause and cancer-related mortality show a diverse regional pattern beyond the known East-West mortality divide. A generalized approach of the avoidable/amenable cancer mortality definition is applied for suitable regional comparisons of long-term trends.

Methods: Standardized death rates of preventable and amenable cancer mortality for men and women were computed for the period 1990-2014 to observe sex-specific excess mortality due to specific cancers after the German reunification. For regional comparison, three German super regions were defined in Eastern, Northwestern, and Southwestern Germany to account for similarities in long-term regional premature and cancer-related mortality patterns, socioeconomic characteristics, and age structure.

Results: Since preventable and amenable cancer mortality rates typically have driven the recent trends in premature mortality, our findings underline the current regional pattern of preventable cancer mortality for males with disadvantages for Eastern Germany, and advantages for Southwestern Germany. Among women, the preventable cancer mortality has increased in Northwestern and Southwestern Germany after the German reunification but has decreased in Eastern Germany and converged to the pattern of Southwestern Germany. Similar patterns can be observed for females in amenable cancer mortality.

Conclusions: Although the "traditional" East-West gap in preventable cancer mortality was still evident in males, our study provides some hints for more regional diversity in avoidable cancer mortality in women. An establishing north-south divide in avoidable cancer mortality could alter the future trends in regional cancer-related mortality in Germany.

Keywords: demography, avoidable mortality, cancer mortality, regional differences, gender gap, Germany 


\section{BACKGROUND}

The regional variation in avoidable cancer mortality for Europe is known as a northwest (NW) to southeast (SE) gradient with higher mortality risk proportions for males (1-3). The NW to SE gradient in Europe is also accounted by the increasing smokingrelated cancer incidence and the associated higher mortality risks especially for men in Southeast Europe. Otherwise, in North and West Europe, the cancer incidences tend to be stabilizing because of lower smoking prevalence in men and improved breast cancer screening technology in females (4).

On the regional level, Germany has experienced such geographic variations, with dramatic gaps in cancer-related mortality in the 1970s and 1980s. Prior to the German reunification, the cancer mortality was almost higher in East Germany, similar to the remaining mortality gap between Southeast and Northwest Europe $(4,5)$.

Within the last 25 years, East Germany has passed through an intensive economic and political alteration as well as the assimilation of the health care system under the same conditions of West Germany. This led to a partial adjustment of cancer related mortality in East Germany to the level of West Germany. Moreover, the regional pattern in avoidable cancer mortality known as a northeast-southwest divide still remains (6-8). Plausible explanations yield on a gender gap in avoidable cancer mortality, which tends to be higher in Eastern Germany. That is due to the remaining unfavorable life time risks in that region, especially in its rural areas.

In Eastern Germany, especially in its northern part, men potentially have higher risk of premature deaths because of less willingness of healthcare screening, high smoking and alcohol consumptions levels, overweight, and low physical activity (911). These harmful health behaviors also correspond with social factors and individual lifestyle choices in males.

Men in Eastern Germany are also more likely to be affected from poorer socioeconomic conditions, including redundancy, low income, and lower educational attainment that is also associated with unhealthy behavior $(12,13)$.

After German reunification, Eastern Germany experienced an increase of average life expectancy but also a decrease of birth rates and selective emigration of young and well-educated people, each resulting in an accelerated population aging. Regions with better job opportunities are attractive migration destinations. So far, migration is accounted as a selective health mechanism, with migrants usually being healthier than the stayers (14). In addition, the east-west migration balance is particularly negative among young women, resulting in a tremendous deficit in females among young to middle-aged adults in the rural areas of Eastern Germany (15).

The excess female emigration at county level can be explained with gender disparities in educational attainment that favored women (15). The female brain drain in Eastern Germany is also accompanied with less availability of potential partners for men $(15,16)$. The selective migration pattern accompanied by the loss in positive health risk factors as well as the discrepancy in sex-specific health behaviors are good indicators to explain regional variation in avoidable cancer mortality. Therefore, we use the gender gap in avoidable cancer mortality as a proxy for regional variation in the distribution of biological and nonbiological factors $(17,18)$. Some studies argue that only $25 \%$ of the sex differences in mortality are attributable to biological differences (18). The major part can be explained by social and behavioral factors, which are in turn influenced by biological factors, however (19).

The major scope of our study was to analyze the regional longterm trends in avoidable cancer mortality for the period since the German reunification under consideration of a generalized approach for the avoidable cancer mortality definition that is suitable for the German regional perspective.

Moreover, we examined sex-specific disparities in avoidable cancer mortality to explain recent trends to explain the recent trends for three German super regions: Eastern, Northwestern, and Southwestern Germany.

\section{DATA AND METHODS}

Different approaches were used in literature to account for avoidable mortality that had involved different typologies of premature death. Generally, avoidable mortality can be referred to as a selection of causes of death that should be amenable to health care (amenable mortality) or as a selection of causes of death that should be avoidable through primary prevention (preventable mortality) (20). There are many different concepts of avoidable mortality but no commonly used classification of avoidable cancer mortality that includes both amenable and preventable conditions. Regarding the health service system and the national health risk profile in Germany, we have therefore, redistributed the avoidable cancer mortality classification to an approach that is more suitable for the case of Germany. This classification of avoidable cancer mortality and its division into preventable and amenable cancers basically follows the concepts of Nolte and McKee (21), Page et al. (22), Tobias et al. (23), Nolte and McKee (24), and Mackenbach et al. (25).

In the first group of preventable cancer mortality, we selected all cancer-related deaths that could be avoided or reduced through effective inter-sectoral health policies by means of primary prevention, especially with regard to smoking, unhealthy diet, and alcohol consumption. This involved cancers of lip, oral cavity, pharynx, esophagus, stomach, liver, larynx, lung, bronchus, trachea, and bladder.

The second group of amenable cancer mortality includes all cancer-related deaths that should be avoided or reduced through timely and effective health care regarding both, diagnosis and treatment. This involved cancers of colon and rectum, bone, skin, eye, and thyroid as well as Hodgkin's disease and leukemia and the sex-specific cancers of female breast, cervix, uterus, prostate, and testis (Table 1).

For data analysis, we used the cause of death data for the period of 1990-2014 by sex, age, and regional level (16 German Bundesländer) as well as the corresponding year-end population numbers for the period of 1989-2014, provided by the Federal Statistical Office. In order to avoid fluctuations, three year values were used for all calculations. Thus, the analyses refer to the 
TABLE 1 | Selection of causes of death.

\begin{tabular}{|c|c|c|c|c|}
\hline & Cause of death & Age & ICD-9 & ICD-10 \\
\hline \multirow[t]{5}{*}{ Preventable cancer mortality } & Cancer of lip, oral cavity, pharynx & $0-74$ & $140-149$ & $\mathrm{C} 00-\mathrm{C} 14$ \\
\hline & Cancer of esophagus & $0-74$ & 150 & C15 \\
\hline & Cancer of stomach & $0-74$ & 151 & C16 \\
\hline & Cancer of liver & $0-74$ & 155 & $\mathrm{C} 22$ \\
\hline & Cancer of larynx $x^{a}$ & $0-74$ & 161 & C32 \\
\hline \multirow[t]{5}{*}{ Amenable cancer mortality } & Colorectal cancer & $0-74$ & $153-154$ & C18-C21 \\
\hline & Bone cancer ${ }^{b}$ & $0-74$ & 170 & C40-1 \\
\hline & Skin cancer & $0-74$ & 172,173 & C43, C44 \\
\hline & Eye cancer & $0-74$ & 190 & C69 \\
\hline & Thyroid cancer & $0-74$ & 193 & C73 \\
\hline \multirow{2}{*}{$\rightarrow$ Women only } & Cervical cancer & $0-74$ & 180 & C53 \\
\hline & Uterine cancer & $0-74$ & 179,182 & C54, C55 \\
\hline \multirow[t]{2}{*}{$\rightarrow$ Men only } & Prostate cancer ${ }^{a}$ & $0-74$ & 185 & $\mathrm{C} 61$ \\
\hline & Testicular cancer & $0-74$ & 186 & C62 \\
\hline
\end{tabular}

This classification is based on Page et al. (22), with the following exceptions:

a Laryngeal and prostate cancer were added according to Mackenbach et al. (25).

${ }^{b}$ Bladder and bone cancer were added according to Tobias et al. (23).

${ }^{c}$ Leukemia group was widened according to Nolte and McKee $(21,24)$.

period from 1991 to 2013. The cause-specific death information on cancer was followed to the International Classification of Diseases (ICD) with ICD-9 codes up to 1997 and ICD-10 codes from 1998 onwards. We defined the following age- groups: $0-$ $29,30-39,40-44,45-49,50-54,55-59,60-64,65-69$, and 70-74 years to estimate the age-specific death rates for specific cancers. The bounds of the first two age groups are broader due to the comparatively low numbers of cancer deaths at young ages. Older ages from 75 years upwards were not included "as "avoidability" of death and reliability of death certification become increasingly questionable at older ages" (21).

For regional comparisons, we defined three geographic regions: Eastern, Northwestern, and Southwestern Germany (Figure 1). This geographical grouping is based on minimal internal group variation in the level of cancer mortality and its development over time as well as similarities in socioeconomic characteristics and age structure. Eastern Germany corresponds to the territory of the former GDR (East Germany), however including all of Berlin. Western Germany, thus excluding the city of Berlin, was divided into a northern and southern part to take account of systematic differences in mortality and socioeconomic characteristics, which otherwise would be overlaid. Doing this, both gradients, between north and south as well as between east and west, can be addressed.

The rates of preventable and amenable cancer mortality for men and women were computed for the period from 1991 to 2013 to observe sex-specific differences in specific cancers after the German reunification. We used standardized death rates to show all-cause and cause-specific mortality differences over time and between regions and sex. The main advantage of standardization is that death rates are no longer distorted by differences or changes in the age structure. Furthermore, standardized death rates are additive: "the sum of death rates by cause equals the death rate from all causes" (Meslé, 2006, p. 36) (26). Death rates with a directly standardized age and sex structure were therefore, computed for each region, differentiated by sex and cause of death group, based on textbooks like Preston et al. (27) but were adjusted for the use of 3 year periods and year-end population statistics:

$S D R_{t}=\sum_{x}\left(\frac{D_{x ; t-1}+D_{x ; t}+D_{x ; t+1}}{0.5 \cdot N_{x ; t-2}+N_{x ; t-1}+N_{x ; t}+0.5 \cdot N_{x ; t+1}} \cdot C_{x}\right)(1)$

with $S D R_{t}$ being the standardized death rate at time $t$ (in years); $D_{x}$ being the number of deaths at age $x, N_{x}$ being the age-specific year-end population size, and $C_{x}$ being the agespecific standard population. We chose the German 2011 Census as standard population without disaggregation by sex. As a statistical test for the standardized death rates, we calculated $95 \%$ confidence intervals according to Chiang (28), with the agespecific probability of death computed according to Farr (29). We interpreted mortality differences at time $t$ as statistically significant when the confidence intervals of two regions did not overlap.

For relative comparison we used rate ratios from standardized death rate estimates, with Southwestern Germany as the reference population. 


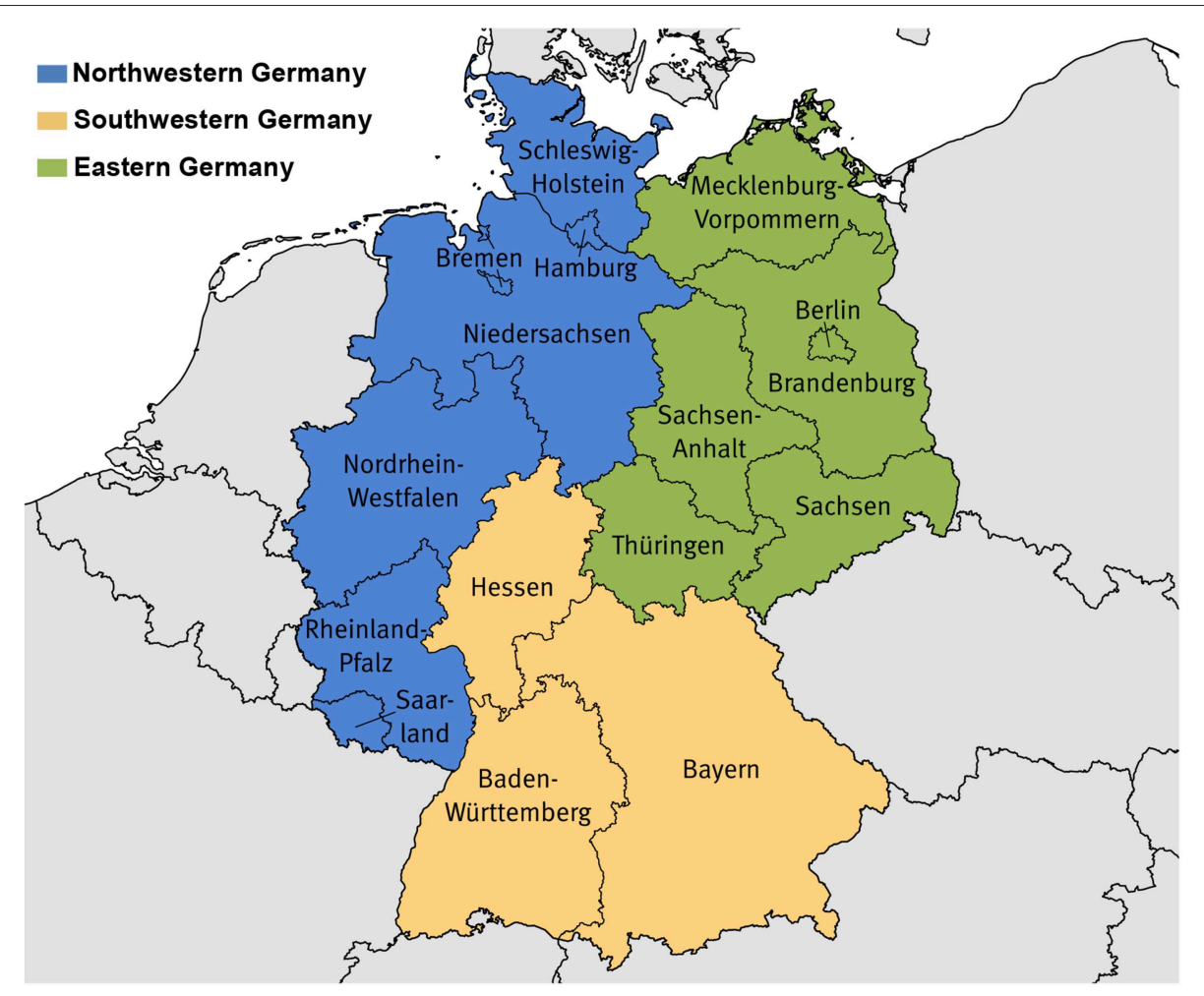

FIGURE 1 | Composition of the study regions. Northwestern Germany: Bremen, Hamburg, Niedersachsen, Nordrhein-Westfalen, Rheinland-Pfalz, Saarland, Schleswig-Holstein; Southwestern Germany: Baden-Württemberg, Bayern, Hessen; Eastern Germany: Brandenburg, Berlin, Mecklenburg-Vorpommern, Sachsen, Sachsen-Anhalt, Thüringen. Base map: ${ }^{\circledR}$ GeoBasis-DE/Bundesamt für Kartographie und Geodäsie.

\section{RESULTS}

Overall, we find declining trends in preventable and amenable cancer mortality, comparable to the decrease in all-cause premature mortality (see Figure A1). In addition, avoidable cancer deaths contribute to one third of all premature deaths among men and to almost half of all premature deaths among women (see Table A1). Thus, we identify the decrease in avoidable cancer mortality as one of the major drivers for the decrease in German overall mortality at ages 0 to 74 . The avoidable cancer deaths in all-cause premature mortality in Germany increased from 30 to $34 \%$ among men and rose from 41 to $48 \%$ among women between 1991 and 2013 due to the stronger decrease in other premature deaths. This relative growth is evident for all regions, but particularly for Eastern Germany, which shows an increase from 25 to $33 \%$ among men and from 34 to $45 \%$ among women. While avoidable cancer mortality is dominated by preventable cancer deaths among males, amenable cancer deaths are more prominent among females.

For men, preventable cancer mortality decreased by $29 \%$ in Eastern Germany, 34\% in Northwestern Germany, and about 36\% in Southwestern Germany between 1991 and 2013 (see Table A2). The relative decrease in amenable cancer mortality is similar among men: $28 \%$ in Eastern Germany, 32\% in Northwestern Germany, and 36\% in Southwestern Germany. Among women, however, the trend in preventable cancer mortality is diametrically opposed as there is an overall increase in all three regions. Amounting to $27 \%$, the relative growth in preventable mortality is more present in Northwestern Germany, compared to $19 \%$ in Southwestern Germany and $1.4 \%$ in Eastern Germany. With regard to amenable cancer mortality, the pattern for women is similar compared to men, but showing a slightly higher relative decline: 40\% in Eastern Germany, 35\% in Northwestern Germany, and 37\% in Southwestern Germany.

Furthermore, we find remarkable sex-specific differences in preventable cancer mortality (Figure $2 \mathbf{A}$ ) at the regional level. For men, in spite of a strong decrease in all regions, there is still a considerable east-west divide in the northern half of Germany but there is also an even more significant north-south divide in Western Germany. In 2013, preventable cancer mortality was significantly higher in Eastern $(+32 \%)$ and Northwestern Germany $(+25 \%)$ than in Southwestern Germany among men, approved by mortality rate ratios calculated on the basis of the standardized death rates (see Table A3). Among women, however, preventable cancer mortality has increased in all of Western Germany since reunification but had decreased in Eastern Germany until the late 2000s and since then it has almost converged to the pattern of Southwestern Germany. In comparison to Southwestern Germany, preventable cancer mortality was significantly higher for women in Northwestern $(+34 \%)$ and Eastern Germany $(+4 \%)$ at the end of the observation period. 
A

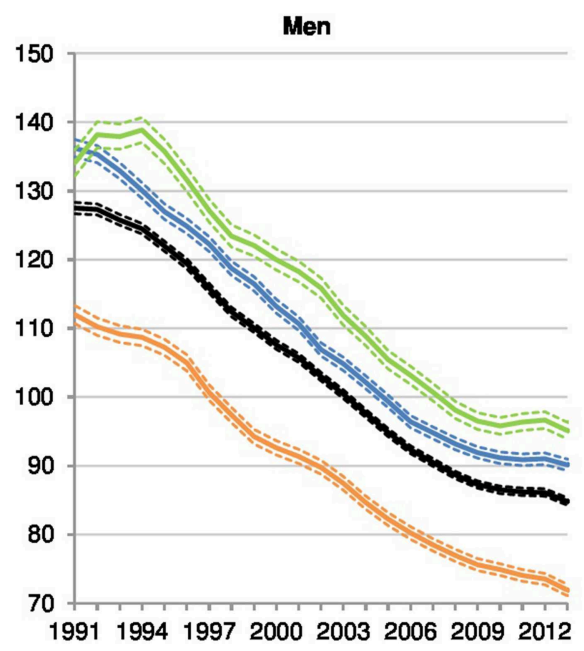

B

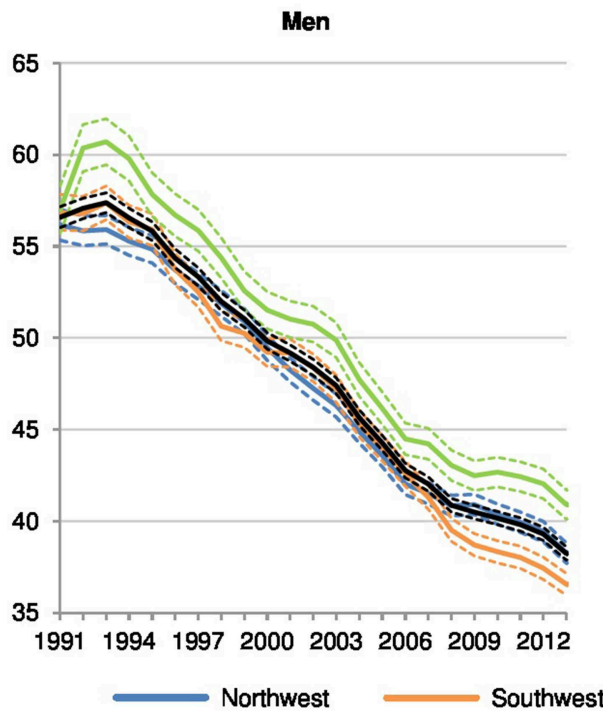

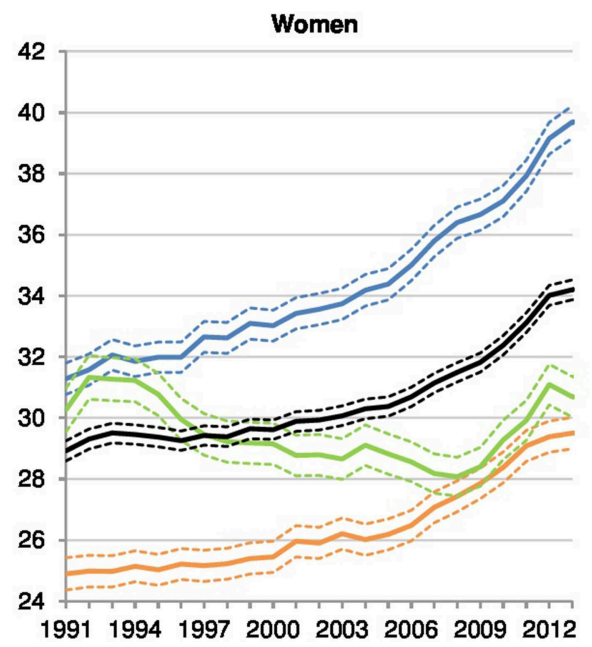

Women

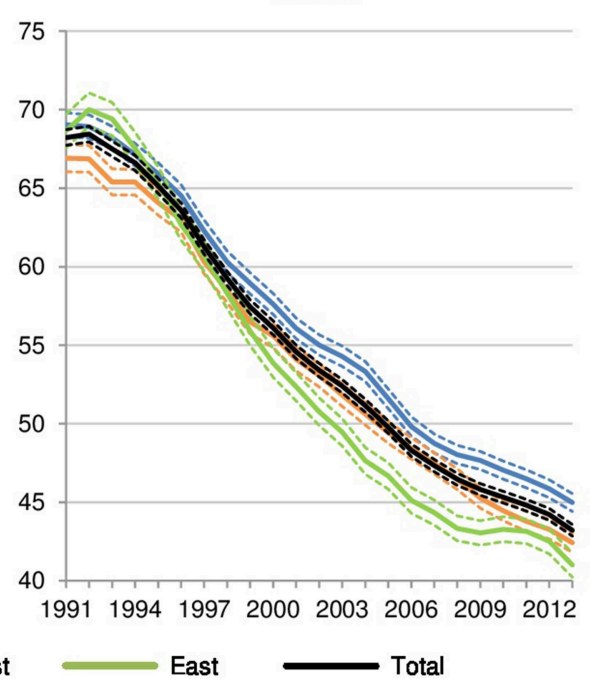

FIGURE 2 | Preventable and amenable cancer deaths per 100,000 in Northwestern, Southwestern, and Eastern Germany (standardized death rate, ages 0-74, years 1991-2013, 3 year values with 95\% confidence intervals). (A) Preventable cancer mortality. (B) Amenable cancer mortality.

Regarding amenable cancer mortality (Figure 2B), regional disparities for men and women are considerably smaller. The known east-west divide still dominates among men $(+12 \%$ in Eastern Germany and $+5 \%$ in Western Germany compared to the southwest in 2013) but a north-south gradient in Western Germany has developed in recent years as well. Among women, the pattern has become increasingly determined by a north-south gradient in Western Germany. In comparison to the southwest, amenable cancer mortality was significantly higher in the northwest $(+6 \%)$, while Eastern Germany $(-3 \%)$ showed the lowest level among the three regions in the last year of observation.

Dividing amenable cancer mortality into sex-specific and other cancer deaths, the level in sex-specific amenable cancer mortality is generally lower in men than in women since menspecific cancers are less frequent and less likely fatal than womenspecific cancers (Figure 3A). Among men, there is a significant north-south divide to the advantage of the southwest but no systematic differences between Northwestern $(+13 \%$ in 2013 compared to the southwest) and Eastern Germany (+15\%). Among women, however, the pattern is completely different: Northwestern Germany $(+5 \%)$ showed the highest rates, while Eastern Germany $(-7 \%)$ showed the lowest values in comparison to the southwest.

Referring to other amenable cancer deaths (Figure 3B), the regional pattern which favors men and women in Southwestern Germany and disadvantages men in Eastern Germany and females in Northwestern Germany becomes visible again. 

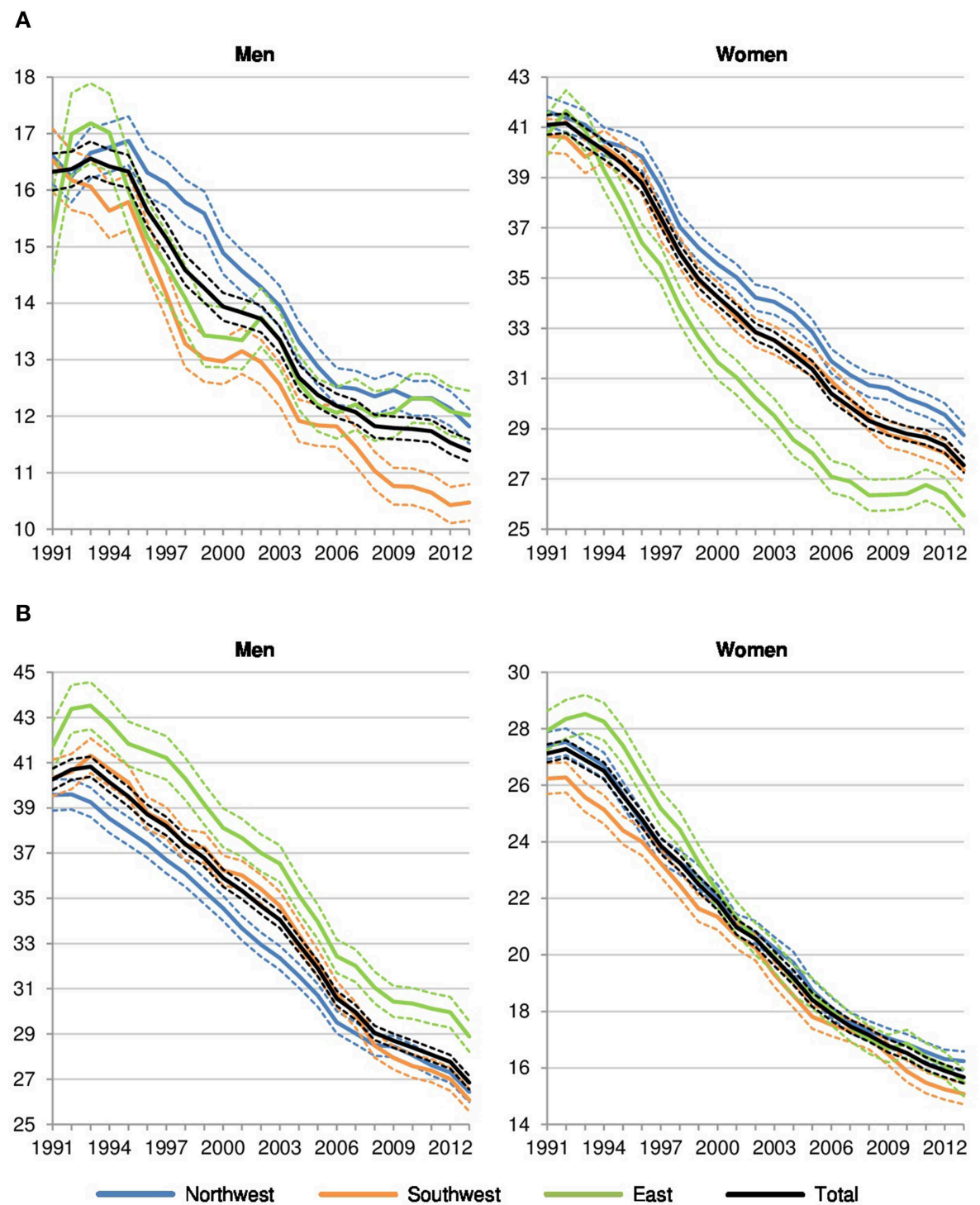

FIGURE 3 | Sex-specific and other amenable cancer deaths per 100,000 in Northwestern, Southwestern, and Eastern Germany (standardized death rate, ages 0-74, years 1991-2013, 3 year values with 95\% confidence intervals). (A) Sex-specific amenable cancer mortality. (B) Other amenable cancer mortality.

All in all, the analyses show that the "traditional" eastwest gap in avoidable cancer mortality is still evident among men, while the north-south gradient has gained importance, with tendency to higher regional diversity. Among women, the northwest of Germany seems to be increasingly left behind the other two regions.

\section{DISCUSSION}

\section{Preventable Cancer Mortality}

Down warding drifts in smoking prevalence for sex and between geographical regions are used to explain the lung cancer mortality disparities in Germany which are mostly responsible for the decline in preventable cancer mortality (30-32). Hence, some regional disparities in preventable cancer mortality for men and women remain evident. In contrast to the "traditional" eastwest gradient $(33,34)$ in preventable cancer mortality, some regions in the East, especially for women, have not exceeded these regional mortality disadvantages as we know from males for the last decade.

With respect to the recent regional cluster affiliations, the female preventable cancer mortality, e.g., for the state of Sachsen, are more likely to take over the regional pattern of Southwestern Germany with more similarities to States of Bayern and BadenWürttemberg and Hessen (all three in vanguard position in preventable mortality) than to other regions in Northwestern Germany (including Bremen, Hamburg, Niedersachsen, Nordrhein-Westfalen, Schleswig-Holstein, Rheinland-Pfalz, Saarland). The assimilation process in Eastern Germany to the Southwestern German pattern can be explained with the 
loss of demographic impact of those age groups with high smoking epidemic in Eastern German women. Female Cohorts born between 1946 and 1950 have not showed any significant differences in smoking behavior in East Germany regarding their educational status (35). But women in West Germany predominantly have a higher smoking risk at the same time.

A recent study on the future perspective in smokingrelated mortality in Germany (36) argues that the east-west convergence and especially the female mortality advantage in Eastern Germany in lung cancer-related mortality is caused by women born in the 1940s and 1950s who showed a comparatively low smoking prevalence. Possibly, the contemporary mortality advantage for women in Eastern Germany will change to the opposite as younger cohorts of Eastern German women show much higher smoking rates in comparison to both, previous cohorts and the West $(36,37)$.

The female lung cancer epidemic affecting the younger cohorts can be approximated. For women, a greater excess mortality for lung cancer is more plausible because of the increasing dominance of higher lung cancer rates in young and middle-aged women (36-38).

The remaining gender gap in preventable cancer mortality is due to lower risks of premature mortality in women. Moreover, the majority of women's sex-specific are amenable cancer deaths is dominated by breast cancer. For men, more unfavorable lifestyle risk factors including social and health behavior need to be examined to analyze male excess mortality $(39,40)$. Those risk factors are largely avoidable and contribute to the human, social, and economic burden that is largely invisible in the epidemiologic literature.

\section{Amenable Cancer Mortality}

Amenable cancer mortality in Germany is also directed by colon/bowel cancer in men and breast cancer in women. The regional pattern in amenable deaths from cancer is more likely driven by the north-south gradient than by the eastwest gap. Overall, the most favorable trends in amenable cancer mortality are still driven by improved therapeutic procedures and advancements in diagnosis and screening that positively affects typically more female cancers. A study from Brenner et al. (41) supports the general improvement in bowel cancer for men and women. After the introduction of screening colonoscopy starting at age 55 years in Germany, the incidence and mortality of bowel cancer have declined in the first decade of the twenty-first century (41). Although the mortality in bowel cancer has systematically declined for both sexes, females exhibit a survival benefit in this type of cancer compared to males. This can be explained the higher willingness of participation in cancer screening programs of women and their appropriated compliance during cancer therapy (41-43).

The most positive trends in amenable cancer mortality are revealed in breast cancer in Germany, because of tremendous improvement in treatment strategies of these cancer sites that had similar benefits for women in East and West Germany (44-47). Although breast cancer is defined as amenable cancer, there is a remaining gap between East and West Germany with unexpected lower incidences and mortality in breast cancer for the East. Those are not typically results only from improvements in therapeutic effects. Thereof, these regional disparities are explained with the variability in reproductive histories for East and West German women $(48,49)$. East German women born in the 1950s and 1960s were less frequently childless and their mean age at first childbirth was 5 years below the value for West German women (50). These two characteristics are important preventive factors in connection with breast cancer (49).

In addition, Eastern Germany, especially the federal state of Sachsen, took over a vanguard position in establishing regional (centralized) cancer registries including certified tumor centers/boards, which should positively affect the amenable cancer mortality trends. Consequently, there is a clear regional pattern in breast cancer mortality with the lowest mortality rates being found in Eastern Germany (Berlin, Brandenburg, Mecklenburg-Vorpommern, Sachsen, Sachsen-Anhalt, Thüringen) and the highest mortality rates in Northwestern Germany (including Schleswig-Holstein, Bremen, Hamburg, Niedersachsen) (51-53). Among women, there is a significant divide between Northwestern Germany and the other two study regions that is probably about to even increase in the near future. Thus, there is an evidence of a manifested Northwest-Southeast divide in amenable and preventable cancer mortality among women.

\section{Limitations}

This study has applied a specific approach to capture the unique difficulties in defining avoidable cancer mortality for the regional comparison in Germany. At the same time, we recognized that some limitations remain. First, we could not consider an additional set of variables, especially all risk factors that were relevant in the development of avoidable cancer mortality. Consequently, this important information on the determinants of cancer mortality such as lifestyle (nutrition, physical activity, alcohol consumption) or environmental conditions (air pollution) was either not available for this recent statistical analyses or was not considered to be representative on the level of the three German super-regions. Socio-economic factors, which significantly influence the relevant risk factors and show considerable regional variations in Germany (40), are not included in official German data. Second, we did not use the data of the German cancer registries, which are recorded by the Association of Population-Based Cancer Registries (GEKID) and the Robert Koch Institute (RKI) every two years (54). Actually, these data offer a more precisely overview on cancer-related mortality and morbidity, such as the prevalence of 27 selected cancer sites, but they are only available for the period of 2004-2014 and not for all German Länder and would therefore not match our analytical and data setting.

Third, the long-term comparisons in cancer mortality are affected by time lags. This involves new treatment/therapeutic effects for amenable cancer mortality, developments in health policy, and changes of health risk behaviors for preventable cancer mortality, e.g., strict anti-smoking policy or healthy food programs (55). Amenable cancer mortality is also a quality benchmark for health care services. As an example, 
the advancement in treatment like adjuvant therapy or recent reimbursement policy in pharmaceuticals may contribute to the decline in cancer mortality. Fourth, we could not control for selective migration between the German regions. This phenomenon might be plausible to explain the healthy migrant effect and even the changes in exposure of health risks in some regions.

\section{CONCLUSIONS}

Generally, our study showed that regional disparities in avoidable cancer mortality are more related to differences in risk-relevant behavior than differences in the effectiveness of health care. Regional differences in avoidable cancer mortality in Germany were much more significant among men, where the traditional east-west gradient was still evident. However, a general northsouth divide was also evident and is especially significant in preventable cancer mortality among men. By contrast, a north-south gradient in Western Germany meanwhile was determined as the avoidable cancer mortality pattern among women particularly led to an alignment of Eastern Germany to the level of Southwestern Germany. Whereas, the male pattern could be explained by higher rates of smoking and alcohol abuse in the East, the female pattern was largely attributed to the high smoking rates of younger, especially Northwestern German cohorts who increasingly reach the cancer-relevant age.

There were structural deficits in Northwestern and Eastern Germany compared to the Southwest regarding the effectiveness of health care that however didn't touch Eastern German women that much, presumably because they were less often childless and thus less affected by breast cancer.

\section{REFERENCES}

1. Znaor A, van den Hurk C, Primic-Zakelj M, Agius D, Coza D, Demetriou A, et al. Cancer incidence and mortality patterns in South Eastern Europe in the last decade: gaps persist compared with the rest of Europe. Eur J Cancer. (2013) 49(Suppl 7):1683-91. doi: 10.1016/j.ejca.2012.11.030

2. Ait Ouakrim D, Pizot C, Boniol M, Malvezzi M, Boniol M, Negri E, et al. Trends in colorectal cancer mortality in Europe: retrospective analysis of the WHO mortality database. BMJ. (2015) 35:h4970. doi: 10.1136/bmj.h4970

3. Feller A, Mark MT, Steiner A, Clough-Gorr KM. Time trend in avoidable cancer mortality in Switzerland and neighbouring European countries 19962010. Swiss Med Wkly. (2015) 145:w14184. doi: 10.4414/smw.2015.14184

4. Jansen L, Gondos A, Eberle A, Emrich K, Holleczek B, Katalinic A, et al. Cancer survival in Eastern and Western Germany after the fall of the iron curtain. Eur J Epidemiol. (2012) 27(Suppl 9):689-93. doi: 10.1007/s10654-012-9723-5

5. Stang A, Bray F, Dieckmann KP, Lortet-Tieulent J, Rusner C. Mortality of testicular cancer in east and west Germany 20 years after reunification: a gap not closed yet. Urol Int. (2015) 95(Suppl 2):160-6. doi: 10.1159/000381883

6. Mons U. Tobacco-attributable mortality in Germany and in the German Federal States-calculations with data from a microcensus and mortality statistics. Das Gesundheitswesen. (2011) 73(Suppl 4):238-46. doi: 10.1055/s-0030-1252039

7. Sundmacher L, Busse R. The impact of physician supply on avoidable cancer deaths in Germany. a spatial analysis. Health Policy. (2011) 103 Suppl 1:53-62. doi: 10.1016/j.healthpol.2011.08.004

8. Sundmacher L, Gaskins MD, Hofmann K, Busse R. Spatial distribution of avoidable cancer deaths in Germany. J Public Health. (2012) 20(Suppl 3):27988. doi: 10.1007/s10389-011-0441-3
The regional pattern in avoidable cancer mortality has become much more diverse, with decreasing importance of the east-west gap and growing significance of a north-south divide.

German health policies should promote better access to medical care in geographic areas with low population density, especially in Eastern Germany and strengthen the improvement of male-specific compliance in primary prevention. Another provision should be the reduction of the male educational disadvantage which consequently affects the health-related lifestyle. Moreover, substantial investments in the labor market strategies to reduce the selective migration of highly educated young people from the east and north to the southern German metropolitan areas have to be considered.

\section{DATA AVAILABILITY}

The datasets for this manuscript are not publicly available because Data must be requested by data transfer center. Requests to access the datasets should be directed to ronny.westerman@bib.bund.de.

\section{AUTHOR CONTRIBUTIONS}

RW and MM are responsible for the concept and design, drafting the article and revising it, and the final approval of the version to be published. MM performed all statistical analyses.

\section{FUNDING}

RW was funded by the Federal Ministry of Education and Research Zentrales Mortalitäts-Follow-up (Second Funding Period) 01ER1801D.

9. Probst C, Roerecke M, Behrendt S, Rehm J. Socioeconomic differences in alcohol-attributable mortality compared with all-cause mortality: a systematic review and meta-analysis. Int J Epidemiol. (2014) 43(Suppl 4):1314-27. doi: 10.1093/ije/dyu043

10. Vogt V, Sundmacher L, Witzheller KB, Baier N, Creutz T, Henschke C. Mortality related to alcohol and tobacco consumption-a benchmarking of regional trends and levels. Gesundheitswesen. (2016) 78(Suppl 6):378-86. doi: 10.1055/s-0035-1548777

11. Stöckl D, Rückert-Eheberg IM, Heier M, Peters A, Schipf S, Krabbe $\mathrm{C}$, et al. Regional variability of lifestyle factors and hypertension with prediabetes and newly diagnosed type 2 diabetes mellitus: the population-based KORA-F4 and SHIP-TREND studies in Germany. PLoS One. (2016) 11:e0156736. doi: 10.1371/journal.pone. 0156736

12. Doblhammer G, Hoffmann R. Gender differences in trajectories of health limitations and subsequent mortality. a study based on the German Socioeconomic Panel 1995-2001 with a mortality follow-up 20022005. J Gerontol B Psychol Sci Soc Sci. (2010) 65(Suppl 4):482-91. doi: 10.1093/geronb/gbp051

13. Kulhánová I, Hoffmann R, Eikemo TA, Menvielle G, Mackenbach JP. Educational inequalities in mortality by cause of death: first national data for the Netherlands. Int J Public Health. (2014) 59(Suppl 5):687-96. doi: 10.1007/s00038-014-0576-4

14. Razum O, Rohrmann S. The healthy migrant effect: role of selection and late entry bias. Gesundheitswesen. (2002) 64(Suppl 2):82-8. doi: 10.1055/s-2002-20271

15. Kröhnert S, Vollmer S. Gender-specific migration from eastern to western Germany: where have all the young women gone? Int Migr. (2012) 50(Suppl 5):95-112. doi: 10.1111/j.1468-2435.2012.00750.x 
16. Melzer SM. The influnence of regional factors on individual mobility patterns considering east-west migration in Germany. In: Salzmann T, Barry E, James R, editors. Demographic Aspects of Migration.Wiesbaden: VS-Verlag (2010). 203-36.

17. Luy M, Minagawa Y. Gender gaps-life expectancy and proportion of life in poor health. Health Rep. (2014) 25(Suppl 12):12-9. Available online at: https:// www150.statcan.gc.ca/n1/pub/82-003-x/2014012/article/14127-eng.pdf

18. Luy M, Wegner-Siegmundt, C. The impact of smoking on gender differences in life expectancy: more heterogeneous than often stated. Eur J Public Health. (2015) 25(Suppl 4):706-10. doi: 10.1093/eurpub/cku211

19. Janssen F, van Poppel F. The adoption of smoking and its effect on the mortality gender gap in Netherlands: a historical perspective. Biomed Res Int. (2015) 2015:370274. doi: 10.1155/2015/370274

20. Hoffmann R, Plug I, Khoshaba B, McKee M, Mackenbach JP, AMIEHS working group. Amenable mortality revisited: the AMIEHS study. Gac Sanit. (2013) 27(Suppl 3):199-206. doi: 10.1016/j.gaceta.2012.08.004

21. Nolte E., McKee M. Does Health Care Save Lives? Avoidable Mortality Revisited. London: Nuffield Trust (2012).

22. Page A, Tobias M, Glover JD, Wright C, Hetzel DM, Fisher EJ. Australian and New Zealand Atlas of Avoidable Mortality. Adelaide: Public Health Information Development Unit and New Zealand Ministry of Health (2006).

23. Tobias M, Yeh L, Timutimu R. Saving Lives, Amenable Mortality in New Zealand 1996-2006. Wellington: Ministry of Health. (2010). Available online at: https://www.health.govt.nz/system/files/documents/publications/ saving-lives-amenable-mortality-in-nz-v2_0.pdf

24. Nolte E, McKee CM. In amenable mortality-deaths avoidable through health care-progress in the US lags that of three European countries. Health Aff. (2012) 31(Suppl 9):2114-22. doi: 10.1377/hlthaff.2011.0851

25. Mackenbach JP, Kulhánová I, Menvielle G, Bopp M, Borrell C, Costa G, et al. Trends in inequalities in premature mortality: a study of 3.2 million deaths in 13 European countries. J Epidemiol Community Health. (2015) 69(Suppl 3):207-17. doi: 10.1136/jech-2014-204319

26. Meslé F. Medical causes of death. In: Caselli G, Vallin J, Wunsch GJ, editors. Demography: Analysis and Synthesis. A Treatise in Population Studies. Amsterdam: Elsevier (2006). p.29-44.

27. Preston SH, Heuveline P, Guillot M. Demography. Measuring and Modeling Population Processes. Oxford: Blackwell Publishers (2000).

28. Chiang, CL. The Life Table and Its Applications. Malabar, FL: Krieger (1984).

29. Farr, W. On the construction of life-tables, illustrated by a new life-table of the healthy districts of England. Phil Trans Royality Soc. (1859) 149:837-78. doi: $10.1098 /$ rstl.1859.0034

30. Jha P. Avoidable global cancer deaths and total deaths from smoking. Nat Rev Cancer. (2009) 9(Suppl 9):655-64. doi: 10.1038/nrc2703

31. John U, Hanke M. Age- and sex-specific trends in lung cancer mortality over 62 years in a nation with a low effort in cancer prevention. Int J Environ Res Public Health. (2016) 13(Suppl 4):362. doi: 10.3390/ijerph13040362

32. Malvezzi M, Carioli G, Bertuccio P, Boffetta P, Levi F, La Vecchia C, et al. European cancer mortality predictions for the year 2017, with focus on lung cancer. Ann Oncol. (2017) 28(Suppl 5):1117-23. doi: 10.1093/annonc/mdx033

33. Luy M. Mortality differences between western and eastern Germany before and after reunification-a macro and micro level analysis of developments and responsible factors. Genus. (2004) 60(Suppl 3/4):99-141. doi: $10.2307 / 29788825$

34. Carlson E, Hoffmann R. The state socialist mortality syndrome. Pop Res Policy Rev. (2011) 30(Suppl 3):355-63. doi: 10.1007/s11113-010-9192-Z

35. Westphal C, Doblhammer G. The diffusion of smoking in east and west Germany: smoking patterns by birth year. Pop. (2012) 67(Suppl 4):653-70 doi: $10.3917 /$ pope. 1204.0653

36. Vogt TC, van Raalte AA, Grigoriev P, Myrskylä M. German east-west mortality difference: two cross-overs driven by smoking. Demography. (2017) 54(Suppl 3):1051-71. doi: 10.1007/s13524-017-0577-z

37. Myrskylä M, Scholz R. Reversing east-west mortality difference among German women, and the role of smoking. Int J Epidemiol. (2013) 42:549-558. doi: 10.1093/ije/dyt008

38. John U, Hanke U. Lung cancer mortality and years of potential life lost among males and females over six decades in a country with high smoking prevalence: an observational study. BMC Cancer. (2015) 15:876. doi: 10.1186/s12885-015-1807-7
39. Kibele EU. Individual-and area-level effects on mortality risk in Germany, both East and West, among male Germans aged 65+. Int J Public Health. (2014) 59(Suppl 3):439-48. doi: 10.1007/s00038-013-0480-3

40. Kibele EU, Klüsener S, Scholz RD. Regional mortality disparities in Germany: long-term dynamics and possible determinants. Kolner Z Soz Sozpsychol. (2015) 67(Suppl 1):241-70. doi: 10.1007/s11577-015-0329-2

41. Brenner $H$, Zwink N, Ludwig L, Hoffmeister M. Should screening colonoscopy be offered from age 50? Results from a statewide pilot project, and from a randomized intervention study. Dtsch Arztebl Int. (2017) 114:94100. doi: 10.3238/arztebl.2017.0094

42. Hoffmeister M, Holleczek B, Zwink N, Stock C, Stegmaier C, Brenner H. Screening for bowel cancer: increasing participation via personal invitationa randomized intervention study. Dtsch Arztebl Int. (2017) 114:87-93. doi: 10.3238/arztebl.2017.0087

43. Klug SJ. Colonoscopy in Germany-important steps towards a national screening program. Dtsch Arztebl Int. (2017) 114(Suppl 6):85-6. doi: 10.3238/arztebl.2017.0085

44. Hoffmann R, Plug I, McKee M, Khoshaba B, Westerling R, Looman $\mathrm{C}$, et al. Innovations in health care and mortality trends from five cancers in seven European countries between 1970 and 2005. Int J Public Health. (2014) 59(Suppl 2):341-50. doi: 10.1007/s00038-0130507-9

45. Kaplan HG, Malmgren JA, Atwood MK, Calip GS. Effect of treatment and mammography detection on breast cancer survival over time: 1990-2007. Cancer. (2015) 121(Suppl 15):2553-61. doi: 10.1002/cncr.29371

46. Scharl A, Kühn T, Papathemelis T, Salterberg A. The right treatment for the right patient-personalised treatment of breast cancer. Geburtshilfe Frauenheilkd. (2015) 75(Suppl 7):683-91. doi: 10.1055/s-0035-1546270

47. Harbeck N, Gnant M. 2017 Breast cancer. Lancet. (2017) 389(Suppl 10074):1134-50. doi: 10.1016/S0140-6736(16)31891-8

48. Hank K. Childbearing history, later-life health, and mortality in Germany. Pop Stud. (2010) 64(Suppl 3):275-91. doi: 10.1080/00324728.2010.506243

49. Medenwald D, Vordermark D, Dietzel CT. Cancer mortality in former East and West Germany: a story of unification? BMC Cancer. (2017) 17:94. doi: 10.1186/s12885-017-3086-y

50. Kreyenfeld M. Crisis or adaptation-reconsidered: a comparison of east and west German fertility patterns in the first six years after the 'Wende'. Eur J Popul. (2003) 19(Suppl 3):303-29. doi: 10.1023/A:1024992712815

51. Albert US, Wagner U, Kalder M. Breast cancer in Germany. Breast Care. (2009) 4:225-30. doi: 10.1159/000231981

52. Wallwiener M, Brucker SY, Wallwiener D and The Steering Committee. Multidisciplinary breast centres in Germany: a review and update of quality assurance through benchmarking and certification. Arch Gynecol Obstet. (2012) 285(Suppl 6):1671-83. doi: 10.1007/s00404-011-2212-3

53. Katalinic A, Pritzkuleit R, Waldmann A. Recent trends in breast cancer incidence and mortality in Germany. Breast Care. (2009) 4(Suppl 2):75-80. doi: $10.1159 / 000211526$

54. A Joint Publication of the Robert Koch Institute and The Association of Population-Based Cancer Registries in Germany. Cancer in Germany 2013/2014. 11th ed. Berlin: Robert Koch Institute (2018).

55. GBD 2016 Healthcare Access and Quality Index collaborators. Measuring performance on the Healthcare Access and Quality Index for 195 countries and territories and selected subnational locations: a systematic analysis from the Global Burden of Disease Study 2016. Lancet. (2018) 391(Suppl 10136):2236-71. doi: 10.1016/S0140-6736(18) 30994-2

Conflict of Interest Statement: The authors declare that the research was conducted in the absence of any commercial or financial relationships that could be construed as a potential conflict of interest.

Copyright (c) 2019 Westerman and Mühlichen. This is an open-access article distributed under the terms of the Creative Commons Attribution License (CC BY). The use, distribution or reproduction in other forums is permitted, provided the original author(s) and the copyright owner(s) are credited and that the original publication in this journal is cited, in accordance with accepted academic practice. No use, distribution or reproduction is permitted which does not comply with these terms. 


\section{APPENDIX}

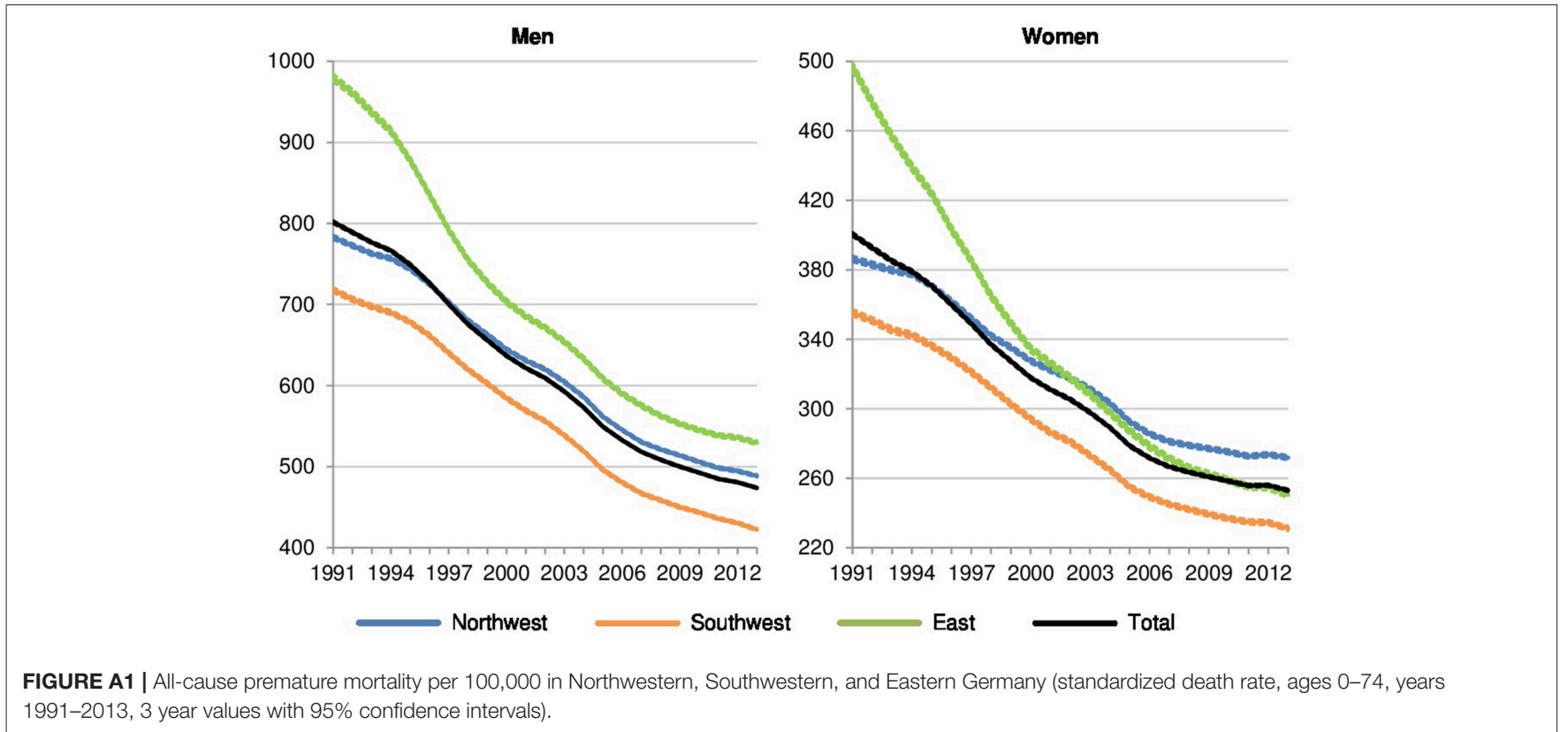

TABLE A1 | Share of preventable and amenable cancer deaths in all-cause mortality at ages 0-74 in 1991 and 2013 for men and women in Northwestern, Southwestern, Eastern, and total Germany (in \%).

\begin{tabular}{|c|c|c|c|c|c|}
\hline & \multirow[t]{2}{*}{ Preventable cancer mortality } & \multicolumn{3}{|c|}{ Amenable cancer mortality } & \multirow[t]{2}{*}{ Total avoidable ca } \\
\hline & & Total & Sex-specific & Other & \\
\hline \multicolumn{6}{|l|}{ Men 1991} \\
\hline Southwest & 15,6 & 7,9 & 2,3 & 5,6 & 31,4 \\
\hline Northwest & 17,4 & 7,2 & 2,1 & 5,1 & 31,8 \\
\hline East & 13,7 & 5,8 & 1,6 & 4,3 & 25,3 \\
\hline Total Germany & 15,9 & 7,1 & 2,0 & 5,0 & 30,0 \\
\hline \multicolumn{6}{|l|}{ Men 2013} \\
\hline Southwest & 17,0 & 8,7 & 2,5 & 6,2 & 34,3 \\
\hline Northwest & 18,4 & 7,8 & 2,4 & 5,4 & 34,1 \\
\hline East & 18,0 & 7,7 & 2,3 & 5,5 & 33,4 \\
\hline Total Germany & 17,9 & 8,1 & 2,4 & 5,7 & 34,0 \\
\hline \multicolumn{6}{|l|}{ Women 1991} \\
\hline Southwest & 8,1 & 17,9 & 10,8 & 7,1 & 43,8 \\
\hline Northwest & 7,0 & 18,8 & 11,4 & 7,4 & 44,7 \\
\hline East & 6,1 & 13,8 & 8,2 & 5,6 & 33,7 \\
\hline Total Germany & 7,2 & 17,0 & 10,3 & 6,8 & 41,3 \\
\hline \multicolumn{6}{|l|}{ Women 2013} \\
\hline Southwest & 12,8 & 18,4 & 11,8 & 6,5 & 49,5 \\
\hline Northwest & 14,6 & 16,5 & 10,6 & 6,0 & 47,7 \\
\hline East & 12,3 & 16,4 & 10,2 & 6,2 & 45,0 \\
\hline Total Germany & 13,5 & 17,1 & 10,9 & 6,2 & 47,7 \\
\hline
\end{tabular}


TABLE A2 | Relative trend in preventable and amenable cancer mortality and all-cause mortality at ages 0-74 between 1991 and 2013 for men and women in Northwestern, Southwestern, Eastern, and total Germany (in \%).

Preventable cancer mortality

Amenable cancer mortality

Premature all cause mortality

Total Sex-specific Other

Men

Southwest

Northwest

East

Total Germany

$-35,7$

$-35,8$

$-33,8$

$-29,1$

$-33,5$

$-31,9$

$-28,2$

$-36,6$

$-35,3$

$-41,2$

Women

Northwest

$+26,9$

$-32,4$

$-21,2$

$-33,2$

$-37,6$

Southwest

$+18,5$

$+1,4$

$-30,2$

$-30,8$

$-46,0$

East

Total Germany

$+18,2$

$-34,8$

$-31,0$

$-33,3$

$-40,9$

$-36,6$

$-40,7$

$-29,6$

$-32,8$

$-42,5$

$-35,0$

$-40,3$

$-37,3$

$-44,6$

$-49,6$

$-33,0$

$-42,2$

$-36,8$

TABLE A3 | Ratio of the standardized death rates in preventable and amenable cancer mortality and all- cause mortality at ages 0-74 in 1991 and 2013 for men and women in Northwestern, Southwestern, Eastern, and total Germany.

Preventable cancer mortality

Amenable cancer mortality

Total

Sex-specific

Other

Men 1991

Southwest

Northwest

East

Total Germany

Men 2013

Southwest

Northwest

East

Total Germany

Women 1991

Southwest

Northwest

East

Total Germany

Women 2013

Southwest

Northwest

East

\section{1}

1,22

1,20

1,14

\section{1}

1,25

1,32

1,18

\section{1}

1,26

1,22

1,16

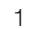

1,35

1,04
1

0,99

1,00

1,00

\section{1}

1,05

1,12

1,05

1

1,03

1,03

1,02

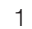

1,06

0,97

\section{1}

1,13

1,15

1,09

1

1,02

1,00

1,01

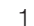

1,05

0,93

\section{1}

1,01

1,11

1,03

1

1,04

1,06

1,03

1

1,08

1,03

$\begin{array}{ccc}1 & 1 & 1 \\ 1,00 & 0,98 & 1,09 \\ 0,92 & 1,04 & 1,36 \\ 0,99 & 1,00 & 1,12\end{array}$

36

,12

\section{1}

1,16

1,25

1,12

1

1,09

1,40

1,13

1

1,18

1,08 